\title{
Development of a high force density, actuation drive for an aerospace application
}

\author{
Michael Galea, Giampaolo Buticchi
}

\begin{abstract}
This paper deals with the design, implementation and experimental validation of a complete, electrical drive system, for linear actuation in an aerospace environment, with the main requirements being high force/power density, reliability, availability and fault tolerance. A directly-driven, linear, high force density, tubular motor supplied from a matrix converter for a rotorcraft application is specifically considered. Design aspects of both motor and converter are presented, while an overview of the implementation aspects for the complete drive system is also given. Precise control structures are proposed and tested. Experimental results are presented and compared to the calculated design values. This work shows how the combination of high performance components can achieve a high performance drive in terms of power density and force density.
\end{abstract}

Index Terms - aerospace, high power/force density, matrix converter, more electric aircraft, tubular motor

\section{INTRODUCTION}

$\mathrm{T}$ HE more electric aircraft (MEA) initiative $[1,2]$ seeks to reduce or remove the reliance on traditional, hydraulic, pneumatic and mechanical systems from aircraft. The concept has been around for the past few decades [1], however improvements in the electrical systems in terms of weight and reliability are still highly required $[3,4]$.

Nowadays, linear force actuation such as required for the control of the primary and secondary flight control surfaces (FCS) is achieved by the use of electro-mechanical actuators (EMA) and/or electro-hydraulic actuators (EHA). Their widespread use is still however limited mainly due to their reliability. A major bottleneck is the probability of jamming, synonymous with the mechanical drive-train of such actuation systems. Adopting direct drive (DD), linear electro-magnetic machines (linear motors) can result in considerable simplifications in terms of the above issues, mainly through the absence of any mechanical gearing and/or ball/roller screws. The main challenge with linear motors is however their inherent inability to achieve the required performance in terms of forceto-mass and force-to-volume ratios as is expected from their mechanically geared, rotational counterparts [5]. A high force density, state of the art, tubular linear permanent magnet (TLPM) motor has been designed and experimentally validated in previous publications $[6,7]$.

In order to drive such a motor, a typical drive system usually makes use of a standard power converter. However, considering the push towards optimizing weight, reliability and fault tolerance of the whole drive system being addressed in this paper (aerospace applications), then it is important to note the typical issues synonymous with standard power converters. In fact, apart from the well-known, low power density values (high relative weight and volume) of such converters, another main issue to consider for the power converter is the damage caused by power cycling and uneven loss distribution among the power devices when the output frequency is similar to that of the input frequency [8]. The output inverter stage of a typical voltage source inverter (VSI) drive will suffer from power cycling issues where the output frequency is close to zero since there will be a slowly changing and unequal loss distribution in the switching devices. The upper devices will suffer an increased loss during the positive output half cycle and similarly the lower device will exhibit an increased loss in the negative half cycle. For the application considered in this work, which involves a constant, position locking operation at stand-still, significant zero speed operation at high load currents is typical and as such a VSI based drive would have to be overrated in order to guarantee longevity. On the other hand, a matrix converter (MC) is a direct AC-AC power converter topology. In the configuration required for this application a three input, three output MC will consist of a 'matrix' of nine bi-directional switches where any input supply phase can be connected to any output load phase at any point in time. With the appropriate control and modulation, the gating of the devices can be modulated to achieve the desired output voltage. The input frequency to the power converter in this case is the 50 or $60 \mathrm{~Hz}$ supply and as such, zero speed load holding is the best condition for thermal cycling [9]. This topology was therefore chosen in order to test and validate the above-mentioned TLPM motor.

Thus, the objective of this paper is mainly to investigate the design aspects and the incorporation of the above high end components into one complete drive that results in a high performance system with excellent performances in terms of power and force density.

\section{Design, Construction AND IMPLEMENTATION}

In this section, brief reviews of the design, construction and implementation of the TLPM motor and the MC as stand-alone devices are given. The design procedures including the analytical modelling of the TLPM motor are presented, while the concept and the design aspects of the $\mathrm{MC}$ are also given. 


\section{A. The TLPM motor}

The design and optimization procedures of the TLPM motor are mainly given in [6]. The single air-gap, double layer, 12slot/10-pole, fluid-cooled, TLPM motor, whose main structure is shown in Fig. 1, is fitted with inset permanent magnets (IPM) and the main design constraint for the machine is the available external envelope.

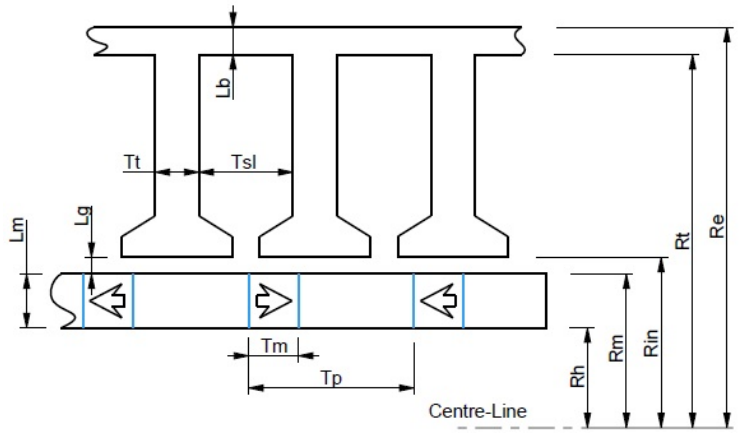

Fig. 1 Structure of the TLPM motor with IPMs

Assuming no iron losses in both stator and mover and neglecting harmonic effects due to the electrical loading, then the no load, air-gap flux density $B_{g}$ can be described by (1), where $B_{\text {rem }}$ is the PM residual flux density and $\mu_{\text {rrec }}$ is the PM relative recoil permeability.

$$
B_{g}=\frac{B_{r e m}}{2} \times \frac{\frac{T_{m}}{\mu_{r r e c}}\left[1-\left(\frac{R_{h}}{R_{\text {in }}}\right)^{2}\right]}{L_{g}\left[1-\left(\frac{R_{h}}{R_{\text {in }}}\right)^{2}\right]+\left(\frac{T_{m}}{\mu_{\text {rrec }}}\right)\left(\frac{T_{c}}{2 R_{\text {in }}}\right)}
$$

The electrical loading $A_{r m s}$ is dependent on the thermal management and material properties of the machine [10]. As shown in [6], the TLPM motor is fitted with a novel, thermal management technique [11], that reduces the thermal resistance from the centre of the stator coils to the cooling arrangement, by the adoption of a high thermal conductivity heat-path (HP). A fluid cooled arrangement is adopted and the thermal/electrical limits can be computed using a lumped parameter, thermal network as shown in Fig. 2, where $R_{1}-R_{12}$ and $R_{H P I}-R_{H P 3}$ are the thermal resistances and whose derivations are given in [11].

Having a maximum permissible winding temperature $T_{\max }$, the maximum value of copper losses $P_{c u}$ for each coil can be found. The maximum value of the copper current density $J_{r m s}$ (and thus $A_{r m s}$ ) can be found from (2), where $\rho_{c u}$ is the resistivity of copper at a given winding temperature and $K_{\text {fill }}$ is the slot fill factor.

$$
P_{c u}=\pi \times T_{s l} R_{h c} K_{f i l l} \times \rho_{c u}\left(R_{t}-R_{\text {tipa }}\right) J_{r m s}^{2}
$$

The peak thrust force $F_{p k}$ generated by the machine can then be computed from (3) where $B_{g l}$ is the fundamental component of the air-gap flux density distribution, $P$ is the number of pole pairs and $\left(4 \pi R_{i n} P T_{p}\right)$ is the total active surface area of the mover.

$$
F_{p k}=B_{g 1} \times\left(\sqrt{2} \times A_{r m s}\right) \times 4 \pi R_{\text {in }} P T_{p}
$$

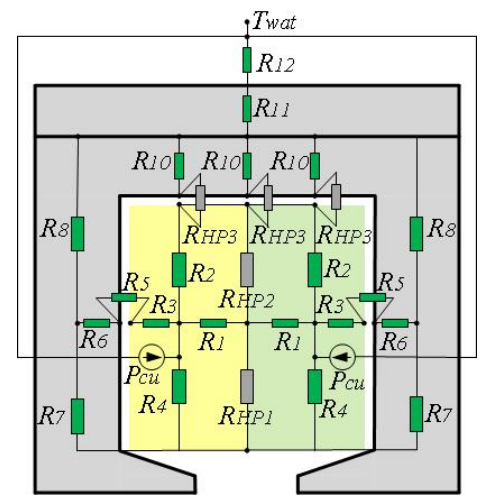

Fig. 2 Lumped parameter thermal network with HP

$$
B_{g 1}=\frac{4 \times B_{g}}{\pi} \sin \left(\frac{\pi}{2} \times \frac{T_{c}}{T_{p}}\right)
$$

Using the above, the optimum split ratio and tooth width to slot width ratio for maximum force can be found. The design is initiated by considering any fixed parameters such as the external length $L_{e}$, external radius $R_{e}$ and $B_{\text {rem }}$ and $\mu_{\text {rrec }}$. Then using (1) - (4), the optimum geometrical dimensions can be found. The analytical models above are used to provide adequate starting points for a more accurate finite element (FE) model, such as shown in Fig. 3.

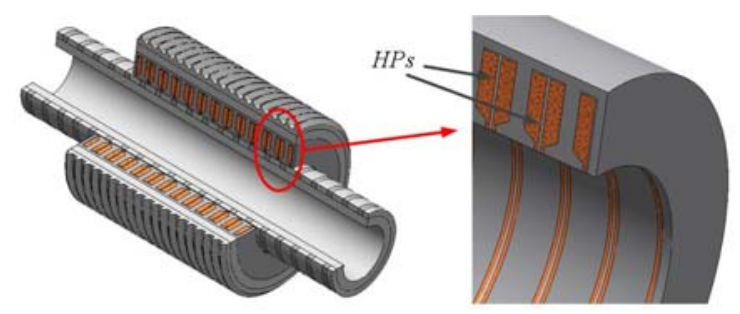

Fig. 3 Final FE model with HPs

A prototype machine of the TLPM motor with fluid cooling and HPs in the slot was manufactured and assembled. Fig. 4 shows a photo of the motor.

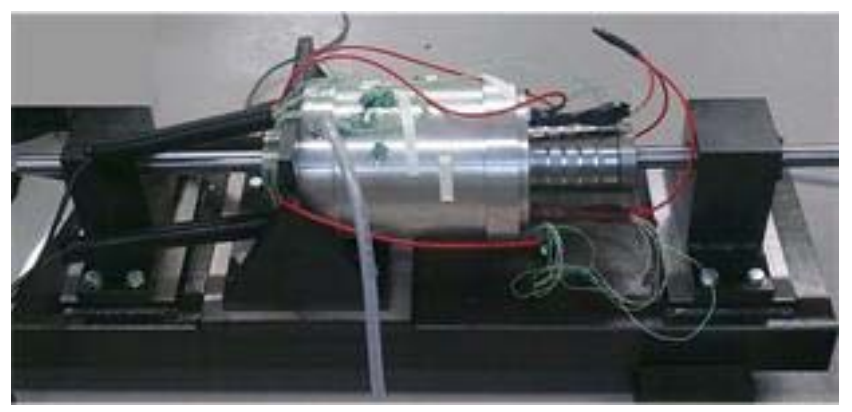

Fig. 4 The TLPM motor prototype

\section{B. The matrix converter}

As mentioned previously and as shown in Fig. 5, the MC for this application uses a matrix of nine bi-directional switches. It is an inherently bi-directional topology and as long as the output power is constant, either DC or sinusoidal AC, the input can be 
made to be sinusoidal and depending on the load conditions, unity displacement factor at the input is also possible. As a direct $\mathrm{AC} / \mathrm{AC}$ solution, a $\mathrm{MC}$ does not require electrolytic $\mathrm{DC}$ link capacitors or large input inductors. A small input filter is necessary to reduce the line side switching harmonics of the system. The lack of bulky, passive components allows the MC technology to offer power and volume density features which are desirable in motor drives for aircraft applications.

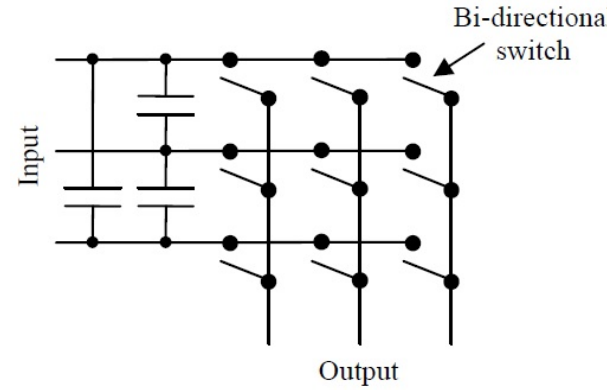

Fig. 5 The 9 switch, 3 phase to 3 phase MC

One potential drawback to this converter is that, in order to ensure a sinusoidal input current, the output voltage transfer ratio is limited to 0.86 . This however is not a drawback, if the required voltage of the load is less than this value, as is the case in this application. In order to implement a MC, a suitable bidirectional switch however must be implemented which can carry both the current in either direction and block the voltage in both directions. Potential arrangements are described and investigated thoroughly in [12].

For this application, a high current, $100 \mathrm{~kW}, \mathrm{MC}$ is used to drive the actuator. It has been designed and constructed using modified E-type industrial power modules. Each module contains three common emitter connected bidirectional switches and hence three of these modules are used to construct the converter. The module uses $1700 \mathrm{~V}, 600 \mathrm{~A}$ IGBTs and $500 \mathrm{~A}$, $1200 \mathrm{~V}$, silicon carbide ( $\mathrm{SiC}$ ) diodes (using $50 \mathrm{~A}$ chips) to reduce the losses associated with the commutation process. The modules are directly mounted onto individual water jacket heat exchangers. Power planes are used to connect the input filter capacitors and the power circuit. A high speed diode bridge clamp with active energy dump, similar to that described in [13] is included to provide fault protection. The converter is controlled using a high speed floating point DSP (C6713) and an FPGA to provide all of the necessary PWM generation and A2D interfaces. The controller implements a space vector PWM generator and has a minimum output vector time of $20 \mathrm{~ns}$ with an edge resolution of $20 \mathrm{~ns}$. High speed, low jitter, fibre optic channels are used to transfer the PWM demand signals to the gate drive circuits.

Considering that the input supply frequency for this application varies in the range of $360-800 \mathrm{~Hz}$ and that the switching frequency is $12.5 \mathrm{kHz}$ then in order to avoid interference between these frequencies and their harmonics, a resonant frequency between 4 to $5 \mathrm{kHz}$ has been initially assumed. A parallel damped single section filter configuration was chosen for this application as shown in Fig. 6, where a resistor is placed in parallel with the inductor to provide appropriate damping according to the value of resistance $R$ selected. A very small value of $R$ would result in a high degree of damping but a higher dissipation of energy.
Simulations of the input filter connected between the input supply and the converter have been run to fine tune the values of both the capacitance, the inductance and the resistor. Due to the necessary AC current rating of the capacitor, several capacitors were used in parallel in order to create $10 \mu \mathrm{F}$ line to line. Three single phase inductors of $50 \mu \mathrm{H}$, rated at $800 \mathrm{~Hz}$ and three $8 \Omega$ resistors have also been implemented.

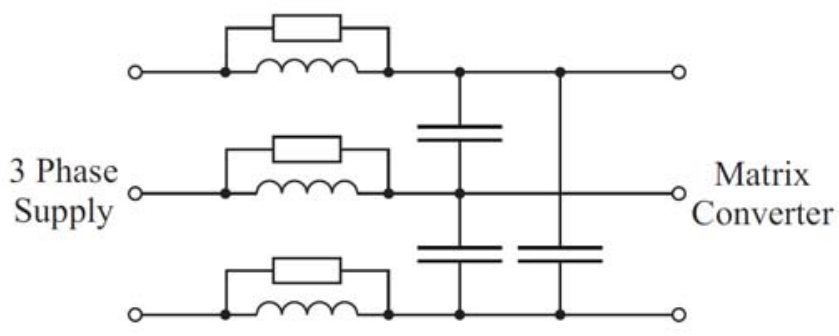

Fig. 6 The MC input filter

One key difference between a VSI and a MC is that there are no freewheeling paths in a MC and as such the commutation of the load current between the input phases without generating input short circuits or output open circuits, needs to be carefully managed. There are many ways of achieving a safe current commutation $[14,15]$ and these can generally be separated into two groups depending on the type of information that is used to derive the switch sequence used.

The process of commutating the current is generally a multistep process. The choice of the commutation technique depends on the requirements of the application but one critical aspect to be considered is the effect on the converter of a commutation process failure. If an overvoltage clamp protection circuit is used then it is preferable to cause an open circuit of the load since there is very little that can be done to protect a power converter from a short circuit of its voltage source and as such, four-step current direction based commutation is used for the power converter.

The derivation of the current direction information needs to be as accurate and noise free as possible. The method uses the inherent voltage drop across the power devices to provide high quality information. The gate drive card for each output phase contains an FPGA which uses the voltage polarity information in order to calculate the current direction in its output phase and perform the current commutations demanded by the controller. The voltage polarity is obtained by measuring the voltage drop across the anti-parallel diode of the IGBT, whose circuit is shown in Fig. 7. A CMOS protection circuit with a resistor $R_{o v}$ and a diode $D_{o v}$ protect the comparator when the diode is blocking the full reverse voltage.
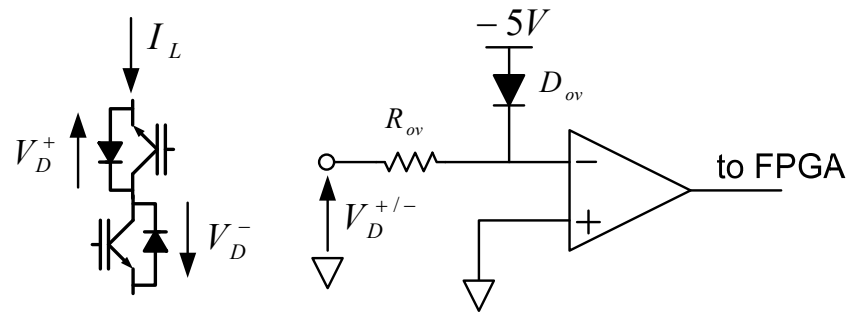

Fig. 7 Current direction detection circuit 


\section{The complete drive}

The MC and the TLPM motor are assembled on a test-rig that comprises an industrial, $40 \mathrm{~kW}$, load EMA capable of peak force loads of up to $17.8 \mathrm{kN}$, with a maximum stroke of $300 \mathrm{~mm}$ at a maximum linear velocity of $313 \mathrm{~mm} / \mathrm{s}$. Fig. 8 shows a photo of the test rig.

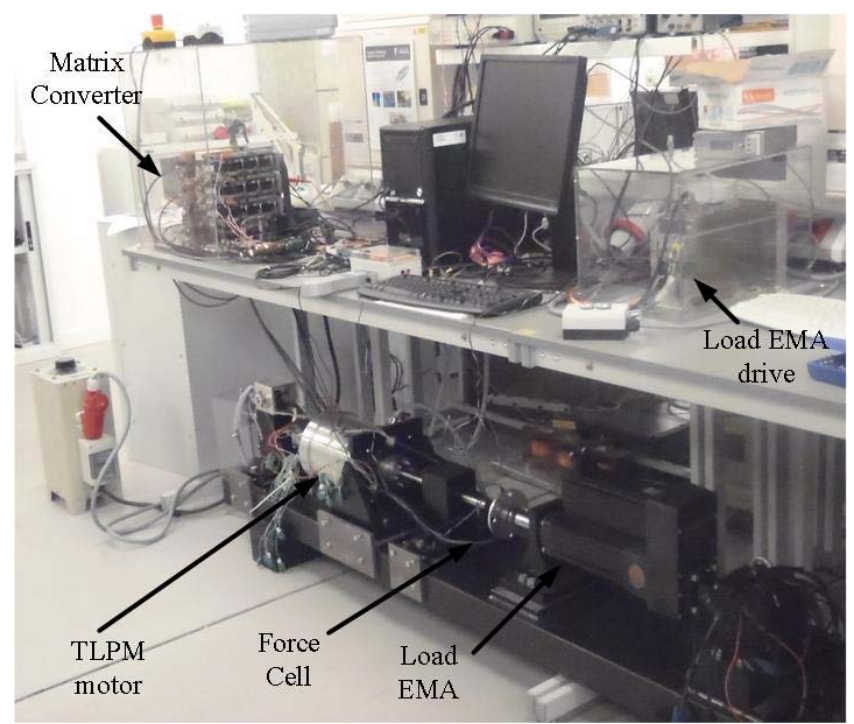

Fig. 8 The test-rig

\section{CONTROL AND EXPERIMENTAL VAliDATION}

In this section, the general control scheme of the system is proposed and presented. The scheme is then used to acquire effective and accurate measurements of the required TLPM motor performances.

The control of the TLPM motor is realized by nested feedback, where the innermost loop is represented by the fieldoriented force control. A linear transducer is employed for the speed and linear position feedback. While optic scales could be employed for this purpose, in this test-rig, a rack-gear coupling was used to convert the linear movement to a rotational one, allowing the use of a standard resolver.

The control of PM synchronous machines (PMSM) has been widely studied in literature, and several methods for the controllers' direct tuning are available in literature [16]. Nested loops are employed in order to accurately limit the maximum acceleration and current. In particular, when the motor is in standstill operations, the FOC is still online. This represents a more advanced control with respect to the positioning system based on stepper motors where the standstill operation is realized by exciting a single phase.

The block scheme of the control of the TLPM motor is shown in Fig. 9. The resolver angle $\theta_{m}$ is processed in order to calculate the linear position $\theta_{l i n}$ and velocity $V_{l i n}$ and the electric angle $\theta_{e}$ employed in the FOC. Simple Proportional-Integral (PI) regulators are employed for the current and speed control, while a Proportional-Derivative (PD) regulator realizes the position loop. At the output of the current regulators the decoupling terms are added. The electrical speed $\omega_{e}$ is calculated from $\theta_{m}$.

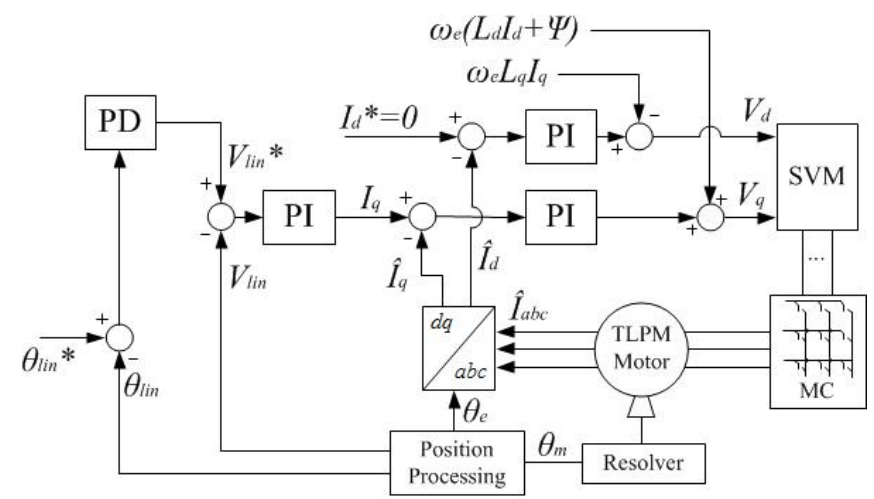

Fig. 9 Control scheme of the complete system

\section{A. No load electro-motive force}

With the MC disconnected, the load EMA is controlled with a square-wave speed demand so as to act as a prime mover that smoothly translates the mover of the TLPM motor at a constant $V_{\text {lin }}$ of $100 \mathrm{~mm} / \mathrm{s}$. Using a high bandwidth oscilloscope, the terminal voltages of the motor are acquired. Fig. 10 shows the excellent agreement between the FE results and the experimentally measured waveforms. The FE waveform shows a slightly higher fundamental, which error can be attributed to experimental tolerances.

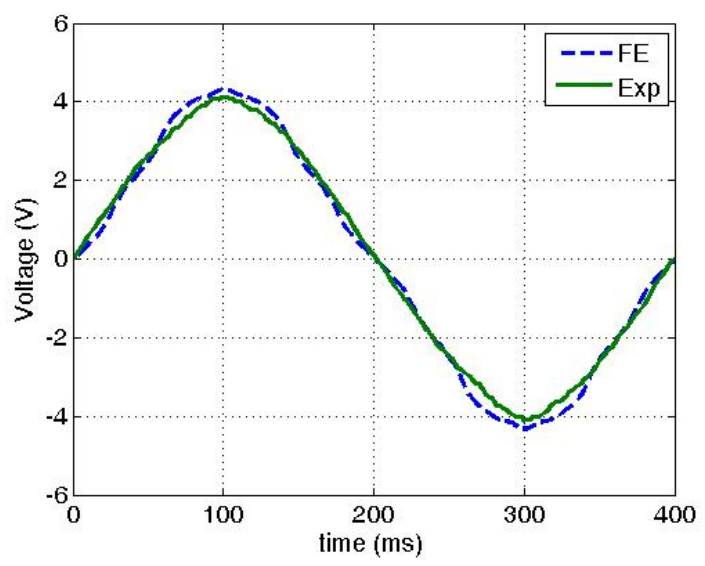

Fig. 10 No load back-EMF

\section{B. Force capability}

In order to measure the force capability of the whole set-up, the control scheme shown in Fig. 9 is used. The EMA is controlled via a precise position loop, with the TLPM motor under current control. The force capability test is thus performed as follows. Taking advantage of the much higher force capability of the EMA (due to the intrinsic mechanical advantage), then it is permissible to start the test by having the mover of the TLPM motor already pushing against the EMA shaft and then utilizing a current ramp in order to reach the required current in the TLPM motor. After a period of operation at the required current, a decreasing current ramp is then performed. The force cell is used to log the force measurements throughout the whole operation. The current demand per phase in terms of the peak value $I_{p k}$ of the TLPM motor is shown in Fig. 11, where the above-mentioned ramps can be observed. 


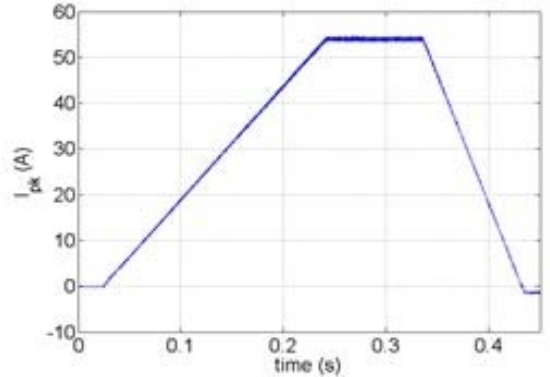

Fig. 11 Current demand of the TLPM motor

For these tests, suitable parameters of the regulators are chosen in order to have a slow increase of the applied force to prevent damage to the force cell. The test is repeated for different positions of the TLPM and averaged in order to be able to neglect the cogging force $F_{c o g}$ from the measured result. Fig. 12 shows the measured results for increasing values of $I_{p k}$ and also compares them to the FE-predicted results. As can be observed in Fig. 12, a very good similarity exists between the predicted and the measured results, thus validating the TLPM motor design procedures and also the control scheme accuracy. Any remaining FE-prediction errors can be attributed to inaccuracies in measurement due to the load cell tolerance $( \pm 1 \%$ of full scale measurement), human error and manufacturing and material properties tolerances.

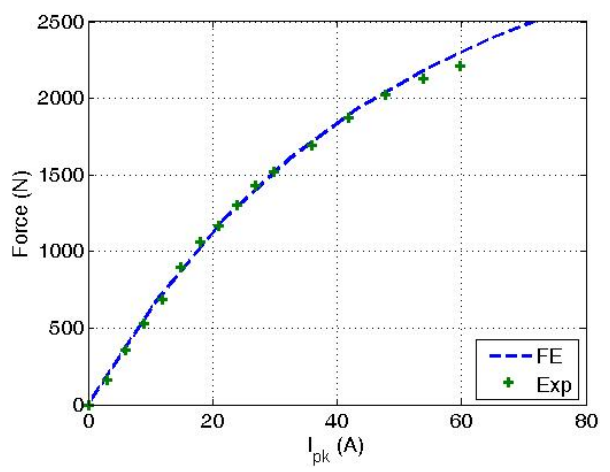

Fig. 12 TLPM motor force capability

\section{Force constant}

The results shown in Fig. 12 can be used to plot the predicted and measured values of the force constant $K_{F}$ of the TLPM motor. Fig. 13 illustrates and compares the FE and experimental results, where it can be observed that for the motor rated value of $I_{p k}=54.05 \mathrm{~A}$, the error between the FE and experimental results is approximately $2.48 \%$.

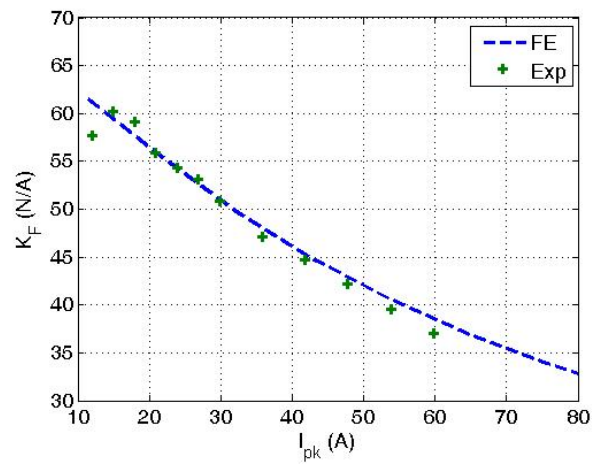

Fig. 13 Force constant $K_{F}$

\section{Cogging force}

Having achieved an accurate characterization of the currentforce capability, it is also possible to indirectly measure the cogging force $F_{\operatorname{cog}}$ of the TLPM motor. To achieve this, the load EMA is mechanically disconnected from the TLPM motor and then position control is used to realize a very slow-moving linear translation of the mover. Neglecting any values of kinetic friction, then this translation motion can be described by (5), where $K_{F}[I(t)]$ represents the $K_{F}$ characteristic shown in Fig. 13 and $m$ is the mass of the mover.

$$
I(t) . K_{F}[I(t)]-F_{\operatorname{cog}}=m \frac{d^{2} \theta_{l i n}}{d t^{2}}
$$

As $\theta_{\text {lin }}$ and $I(t)$ are sampled at a high sampling frequency $(12.5 \mathrm{kHz})$ and $m$ is known from experimental measurement, then the experimental $F_{c o g}$ can be calculated via the numerical method, described by (5). In fact, even if the test is realized with very slow linear speeds, $F_{c o g}$ calculated in this way is affected by a finite $\mathrm{DC}$ component, that corresponds to the linear friction. A high-pass filter can be used to eliminate this DC component from the calculation of $F_{c o g}$.

Fig. 14 illustrates the FE-predicted $F_{\text {cog. }}$. Fig. 15 shows the experimental measures obtained using (5). The difference in the shape of the waveforms can be safely attributed to load cell and material tolerances, while the main cause for the discrepancy is probably the physical presence of ferro-magnetic components (such as the mounting angle-plates, which can be observed in Fig. 4) which are not modelled in the FE model of Fig. 3.

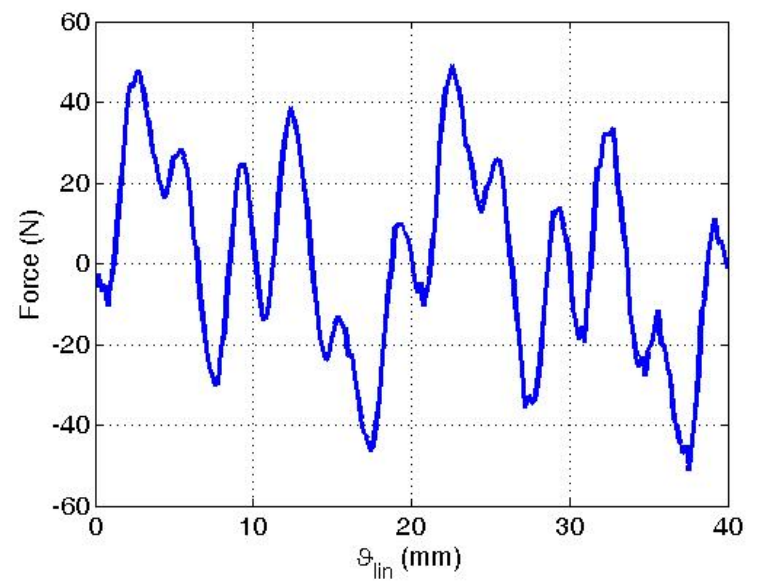

Fig. $14 F_{\text {cog }}$ : FE

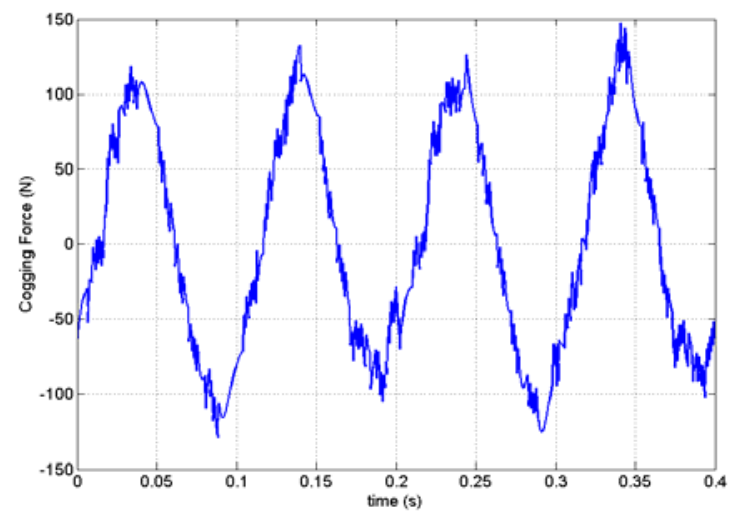

Fig. $15 F_{c o g}$ : experimental 


\section{CONCLUSION}

The experimentally measured, performance capability of the TLPM motor is presented and compared to its predicted capability in Fig. 10 - Fig. 15. The results shown, confirm the reliability of the models used for the design and analysis of the TLPM motor. However they also indicate the high force capability of the manufactured TLPM motor. In fact, with measured force density values of $381.42 \mathrm{kN} / \mathrm{m}^{3}$ and $91.51 \mathrm{~N} / \mathrm{kg}$, the TLPM motor compares excellently with other manufactured prototypes of high force density, linear motors, such as those, whose results are published in available literature $[17,18]$. In this paper, the TLPM motor was "coupled" to a high performance, $\mathrm{MC}$ with a measured power density of $3.85 \mathrm{~kW} / \mathrm{kg}$.

Another advantage of choosing and implementing the $\mathrm{MC}$ topology for the application at hand, where operation is mostly at zero speed resides in the fact that as mentioned and explained in Section I, the thermal stress on the active devices is lower than that of a traditional VSI. This was a major factor in the choice of the converter topology.

In this work, it has been shown how two, high end, state of the art systems such as the TLPM motor and the MC can be successfully implemented into a complete drive system. As illustrated above, the end result is a drive that is capable of satisfying the required application specifications in terms of force and force density while conforming to the highly demanding requirements of reliability, fault tolerance and availability that are so exigent in the aerospace industry.

\section{ACKNOWLEDGMENTS}

This work was partially supported by the Ningbo Science \& Technology Bureaux under Grant 2014A35007.

\section{REFERENCES}

R. I. Jones, "The More Electric Aircraft: the past and the future?," in Electrical Machines and Systems for the More Electric Aircraft (Ref. No. 1999/180), IEE Colloquium on, 1999, pp. 1/1-1/4. A. Boglietti, A. Cavagnino, A. Tenconi, and S. Vaschetto, "The safety critical electric machines and drives in the more electric aircraft: A survey," in Industrial Electronics, 2009. IECON '09. 35th Annual Conference of IEEE, 2009, pp. 2587-2594.

[3] C. Gerada, M. Galea, and A. Kladas, "Electrical machines for aerospace applications," in Electrical Machines Design, Control and Diagnosis (WEMDCD), 2015 IEEE Workshop on, pp. 79-84.
M. Galea, T. Hamiti, and C. Gerada, "Torque density improvements for high performance machines," in Electric Machines \& Drives Conference (IEMDC), 2013 IEEE International, pp. 1066-1073.

G. W. McLean, "Review of recent progress in linear motors," Electric Power Applications, IEE Proceedings B, vol. 135, pp. 380416, 1988.

M. Galea, G. Buticchi, L. Empringham, L. De Lillo, and C. Gerada, "Design of a High-Force-Density Tubular Motor," Industry Applications, IEEE Transactions on, vol. 50, pp. 2523-2532, 2014.

M. Galea, C. Gerada, T. Raminosoa, and P. Wheeler, "Design of a high force density tubular permanent magnet motor," in Electrical Machines (ICEM), 2010 XIX International Conference on, 2010, pp. 1-6.

X. Perpina, X. Jorda, M. Vellvehi, J. Rebollo, and M. MermetGuyennet, "Long-Term Reliability of Railway Power Inverters Cooled by Heat-Pipe-Based Systems," Industrial Electronics, IEEE Transactions on, vol. 58, pp. 2662-2672, 2011.

L. De Lillo, L. Empringham, P. Wheeler, J. Clare, and K. Bradley, "A $20 \mathrm{KW}$ matrix converter drive system for an electro-mechanical aircraft (EMA) actuator," in Power Electronics and Applications, 2005 European Conference on, 2005, pp. 6 pp.-P.6.

C. Sciascera, P. Giangrande, L. Papini, C. Gerada, and M. Galea, "Analytical Thermal Model for Fast Stator Winding Temperature Prediction," IEEE Transactions on Industrial Electronics, vol. 64, pp. 6116-6126, 2017.

M. Galea, C. Gerada, T. Raminosoa, and P. Wheeler, "A Thermal Improvement Technique for the Phase Windings of Electrical Machines," Industry Applications, IEEE Transactions on, vol. 48, pp. 79-87, 2012.

M. Bland, P. Wheeler, J. Clare, and L. Empringham, "Comparison of calculated and measured losses in direct AC-AC converters," in Power Electronics Specialists Conference, 2001. PESC. 2001 IEEE 32nd Annual, 2001, pp. 1096-1101 vol.2.

L. Empringham, L. De Lillo, P. W. Wheeler, and J. C. Clare, "Matrix Converter Protection for More Electric Aircraft Applications," in IEEE Industrial Electronics, IECON 2006 - 32nd Annual Conference on, 2006, pp. 2564-2568.

N. Burany, "Safe control of four-quadrant switches," in Industry Applications Society Annual Meeting, 1989., Conference Record of the 1989 IEEE, 1989, pp. 1190-1194 vol.1.

L. Empringham, P. Wheeler, and J. Clare, "Power density improvement and robust commutation for a $100 \mathrm{~kW} \mathrm{Si-SiC} \mathrm{matrix}$ converter," in Power Electronics and Applications, 2009. EPE'09. 13th European Conference on, 2009, pp. 1-8.

A. Lidozzi, V. Serrao, L. Solero, F. Crescimbini, and A. Di Napoli, "Direct Tuning Strategy for PMSM Drives," in Industry Applications Society Annual Meeting, 2008. IAS '08. IEEE, 2008, pp. 1-7.

N. Bianchi, S. Bolognani, D. D. Corte, and F. Tonel, "Tubular linear permanent magnet motors: an overall comparison," Industry Applications, IEEE Transactions on, vol. 39, pp. 466-475, 2003.

W. Jiabin, W. Weiya, and K. Atallah, "A Linear Permanent-Magnet Motor for Active Vehicle Suspension," Vehicular Technology, IEEE Transactions on, vol. 60, pp. 55-63, 2011. 